\title{
Presentación. Stateville revisited: debates con James B. Jacobs sobre la vigencia de su obra cuarenta años después
}

\author{
Elena Larrauri
}

Universitat Pompeu Fabra. Grupo de Investigación en Criminología y Sistema Penal elena.larrauri@upf.edu

\section{Resumen}

Introducción a la mesa redonda que ofrece una discusión con James B. Jacobs, autor de Stateville: The penitentiary in mass society, un texto clásico en la sociología de prisiones sobre la vigencia de su obra cuarenta años después. Este texto presenta el libro objeto de debate y explica las razones por las cuales sigue siendo hoy en día una obra relevante. En los comentarios que siguen a esta presentación se reflexiona, a partir del debate con el autor, acerca de diversos temas relacionados con su obra y la situación actual de las prisiones en España y en el ámbito internacional. Concretamente, los temas abordados incluyen el papel de los funcionarios en la reforma penitenciaria, el perfil racial de estos, las influencias políticas y sociales en la autoridad en las cárceles, la privatización del castigo, la imposición del orden en las cárceles de mujeres y la educación en prisión.

Palabras clave: prisión; orden; autoridad; burocratización de la prisión; personal penitenciario

* Este estudio se inscribe en el proyecto «Ejecución y supervisión de la pena: Calidad de la intervención, legitimidad y reincidencia» financiado por MINECO (Ref. DER201564403-P), FEDER, UE; y en "Redes de Excelencia» proyecto: Desarrollo de un modelo criminológico y empírico de la política criminal -Acrónimo EmpiriC. Financiado por MCIU-AEI (Ref. DER2017-90552-REDT). 
Abstract. Introduction. Stateville revisited: debates with James B. Jacobs on the validity of his work 40 years later

Introduction to the round table discussion with James B. Jacobs, author of the classic study on the sociology of prisons Stateville: The Penitentiary in Mass Society, on the validity of his work 40 years later. In this introductory text we present the book and discuss why it remains relevant today. The commentaries that follow reflect on various topics examined in Jacobs' book and the current situation of Spanish prisons. More specifically, the issues debated in the round table included the role of prison staff in prison reform and their racial profiles, political and social influences on the transformation of prison authority, the privatization of punishment, the imposition of order in women's prisons and education in prison.

Keywords: prison; order; authority; prison bureaucratization; prison staff

\section{Sumario}

1. La entrada del derecho en la prisión Referencias bibliográficas

2. Stateville revisited

El libro Stateville: The penitentiary in mass society (1977), acerca del cual versó el seminario celebrado en la Universidad Pompeu Fabra en mayo de 2018 para conmemorar los cuarenta años de su publicación, es la tesis doctoral que el profesor James Jacobs realizó entre los años 1972 y 1975 en Stateville, una prisión estatal en Chicago, a la que fue enviado como asistente de investigación de Norval Morris. Su director de tesis fue Morris Janowitz, quien se definía como macrosociólogo, una influencia sin duda visible a lo largo del libro.

La obra de Jacobs es quizás menos conocida en España que otras de la sociología norteamericana, cuyo contenido se ha filtrado a un público más amplio a través de eslóganes como prisonización (Clemmer, 1930), instituciones totales (Goffman, 1961) y penalidades del encarcelamiento (Sykes, 1958). No obstante, creo que todo lector reconocerá en ella muchas ideas que nutren múltiples discusiones contemporáneas. A mi juicio, la obra de Jacobs es bienvenida, por lo menos, por las tres razones que se desarrollarán a continuación.

\section{La entrada del derecho en la prisión}

En primer lugar, el autor describe la transformación del régimen autoritario de la prisión de Stateville en una organización burocrática, gobernada por profesionales y en la cual se empieza a ejercer una forma de autoridad legal racional ${ }^{1}$. Jacobs explica la relación de estas transformaciones internas con los cambios políticos externos. Así, muestra cómo los movimientos a favor de

1. Jacobs se refiere a la distinción de Weber acerca de los tipos de dominación, quien, como es conocido, diferencia entre autoridad carismática, tradicional y legal racional. 
los derechos políticos y civiles propios de la década de los sesenta y setenta en Estados Unidos alcanzan a los presos, quienes también se organizan, aumentan sus expectativas y redefinen, en palabras de Jacobs, su status moral: de sujetos a ciudadanos tras rejas.

Ese cambio de régimen se ve precipitado por la entrada del derecho y los tribunales en la regulación de la vida en prisión. Se pasa de la doctrina de la no intervención (hands off') de los tribunales a una época de activismo judicial en la cual los jueces intervienen sobre las condiciones de vida y en defensa de los derechos constitucionales en la prisión. Las formas de ejercicio del poder en la prisión pasan a estar reguladas, sometidas a normas. En síntesis, la prisión pasa a ser una institución de la que hay que responder.

El trabajo de campo que Jacobs realizó en su momento deja el camino expedito para un análisis actual de la manera cómo los cambios políticos y los discursos externos se filtran al interior de una prisión. Así, por ejemplo, es interesante identificar las formas en que la cultura del control y el populismo punitivo, más allá del crecimiento de las tasas de encarcelamiento, se plasman y son mediados por los agentes dentro de la prisión (Kreager y Kruttschnitt, 2018).

Del mismo modo, la lectura del trabajo de Jacobs invita al análisis de las consecuencias de las sentencias de los tribunales (Reviriego, 2008; Sancha Díez, 2017) en las prácticas en el interior de la prisión (un análisis pendiente, a mi parecer). Esta discusión es tanto más necesaria en cuanto, a pesar de la entrada de los tribunales, prevalece el escepticismo con respecto a la realización de los derechos de los presos. Como indica Jacobs, la entrada del derecho pareciera ser capaz de alterar solo la forma, el procedimiento, pero no los mecanismos a través de los cuáles se (re)produce el control (Owen y MacDonald, 2008).

Un segundo motivo por el cual el libro de Jacobs me parece valioso es porque, al analizar los cambios de régimen de la prisión, él dirige la mirada no solo al colectivo de presos, sino también al personal de vigilancia, al de tratamiento y al director, lo cual le permite captar el sentido de la prisión como una organización social. Por lo que respecta al personal de vigilancia, describe el surgimiento de los sindicatos del personal de vigilancia como respuesta a la autoridad absoluta del director. Estos devendrán una fuerza importante en la prisión y, a su vez, un símbolo de su pérdida de autonomía institucional, al ser una nueva fuerza externa que condicionará la actividad en la prisión. Igualmente, podemos observar el impacto desmoralizador que la entrada de los jueces causa en los funcionarios, pues la limitación de su poder los deja sin armas con las cuales enfrentarse a los presos y hace que estos mismos funcionarios se sientan como el colectivo más controlado.

Por otro lado, la ideología del tratamiento implica la llegada de profesionales específicos a la prisión, y comporta que los vigilantes se sientan observados por una quinta columna que perciben no solo como más cercana al preso, sino también como la encargada de realizar el trabajo agradecido, mientras ellos se ocupan del trabajo sucio (dirty work). Si el personal de vigilancia es desprovisto de su rol dual, por la división operada entre vigilancia y tratamiento, ello afectará a su trabajo, a su concepción, a su rol en la prisión y a las relaciones 
que mantienen con los presos. Sin embargo, sigue siendo intrigante el hecho de que estos vigilantes desmoralizados y controlados sean los que consiguen producir orden, sin que aparentemente tengan que recurrir al uso constante y excesivo de la fuerza. El nuevo poder sometido a normas quizás se ha suavizado, tal vez se ha vuelto más psicológico (Crewe, 2007; 2011) o es posible que se haya desplazado al haber quedado la distribución de algunos beneficios en manos del colectivo del personal de tratamiento.

Sin embargo, la llegada de los nuevos profesionales al amparo de una finalidad rehabilitadora, plasmada fundamentalmente en el modelo terapéutico, no está exenta de tensiones. Estos profesionales chocan con las suspicacias que despierta el tratamiento, inspiran en ocasiones desconfianza en los presos que apenas ven, en los presos con los cuáles tienen una mayor distancia social y defraudan demandas que no pueden atender. No es extraño que en ocasiones se retraigan a sus oficinas.

La lectura del trabajo de Jacobs nos permite por último, acercarnos al impacto que produce entre el personal de vigilancia la llegada de jóvenes directores profesionales, los cuales siempre se ponen del lado de los presos. $\mathrm{Al}$ aplicar un modelo de gestión basado en la eficiencia y altamente centralizado, el personal de vigilancia se encuentra aún más desprovisto del poder que tradicionalmente detentó (y que ya el control judicial y los profesionales del tratamiento habían limitado bastante). De nuevo, Jacobs nos muestra las consecuencias que conllevan los cambios políticos externos, los nuevos modelos de gestión, las nuevas filosofías en el personal que trabaja dentro de una prisión, y la manera cómo ello a su vez impacta en la vida cotidiana de una prisión.

El tercer y último tema que quisiera destacar en el trabajo de Jacobs es su advertencia acerca de las implicaciones de la presencia de una amplísima mayoría de población negra e hispánica en la prisión, hecho al cual asombrosamente los estudios anteriores habían prestado escasa o nula atención.

$\mathrm{Al}$ respecto, el autor observa el realce de las identidades nacionales y religiosas en el colectivo de presos por encima de otras características (no se enfatiza el ser jóvenes pobres excluidos, sino negros musulmanes, Black Muslims). Esta adscripción de los presos a minorías étnicas también muestra cómo un contexto externo intensamente politizado influyó dentro de la prisión y produjo un aumento de litigios y una intervención cada vez mayor de los tribunales en la exigencia de derechos.

Además, empiezan a surgir profundas divisiones raciales en la prisión. Si hasta ese momento podía pensarse en la solidaridad de los presos y en un código carcelario, Jacobs advierte de la nueva organización social interna en la prisión, basada en la existencia de numerosos grupos sociales agrupados en torno a su identidad. Es lo que el autor denomina la balcanización de las prisiones, una situación en la cual el preso percibe la conveniencia de - por lo menos- acercarse a uno u otro grupo.

La existencia de estos grupos influye en la vigencia y eficacia de normas culturales dentro de la prisión, en su capacidad para aliviar las penalidades de la prisión y en la posibilidad de encontrar un nuevo significado al cumplimiento 
de la condena. Además, el surgimiento de estos grupos en un momento de crisis por el cambio de modelo de prisión llena el vacío institucional que se produce en la transición y cumple, así, con las funciones de producir orden, suministrar bienes y proveer seguridad dentro de la prisión (Skarbek, 2011).

\section{Stateville revisited}

Gracias a su trabajo de campo, Jacobs plasmó de forma magistral la transformación de una prisión autoritaria en una organización burocrática legal y los cambios que conllevó la entrada de la ideología del tratamiento en la época posterior a la Segunda Guerra Mundial. El trabajo de Jacobs es, para mí, una inspiración para discutir el derecho presente y la discrecionalidad persistente en la prisión; el poder del personal de vigilancia y el poder implícito en la concesión y retirada de los beneficios (permisos de salida, clasificación en régimen abierto, libertad condicional); los cambios que se producen en el colectivo de los presos, la amplia presencia de colectivos de inmigrantes y el rol que cumplen los grupos dentro de las prisiones.

El objetivo de la mesa redonda que aquí presentamos es debatir con el autor sobre estas y otras cuestiones relevantes de su obra cuarenta años después de su publicación. Con el propósito de reflexionar acerca de los diversos aspectos destacados en esta y ver su evolución y aplicabilidad al momento actual, investigadores de la Universidad Pompeu Fabra, de la Universidad Autónoma de Barcelona y de la Universidad de Gerona plantearon a Jacobs preguntas sobre diferentes temas. Concretamente, los temas abordados incluyen el papel de los funcionarios en la reforma penitenciaria, el perfil racial de estos, las influencias políticas y sociales en la autoridad en las cárceles, la privatización del castigo, la imposición del orden en las cárceles de mujeres y la educación en prisión. Posteriormente, y a partir de las respuestas del autor, se han redactado los textos que presentamos en este debate.

Creemos que estos temas son de especial interés no solo para el análisis de la vigencia y aplicación en la actualidad de algunos de los conceptos presentados en Stateville, sino también porque nos permiten conectar algunas de las ideas más relevantes de la sociología de prisiones con la realidad del contexto español, lo que da lugar a una reflexión más profunda sobre todas estas cuestiones.

Estar en una cárcel y trabajar en ella son experiencias duras, y toda ocasión de discutir cómo garantizar los derechos, suministrar seguridad y reducir el uso de la prisión y el daño que ocasiona es bienvenida. Agradezco, por ello, a todos los participantes en este evento que hayan accedido a realizar este esfuerzo.

\section{Referencias bibliográficas}

Clemmer, Donald (1930). The Prison Community. Chicago: Holt, Rinehart and Winston. $2^{a}$ ed. 1958.

CREWE, Ben (2007). «Power adaptation and resistance in a late-modern men's prison». British Journal Criminology, 47 (2), 256-75. $<$ https://doi.org/10.1093/bjc/azl044> 
CREWE, Ben (2011). «Soft power in prison: Implications for staff-prisoner relationships, liberty and legitimacy». European Journal of Criminology, 8 (6), 455-69. <https://doi.org/10.1177/1477370811413805>

GofFman, Erving (1961). Asylums. Nueva York: Anchor Books.

Owen, Tim y MacDonald, Alison (eds.) (2008). Livingstone, Owen, and Macdonald on Prison Law. Oxford: Oxford University Press, $4^{\mathrm{a}}$ ed.

ReVIRIEGO, Fernando (2008). Los derechos de los reclusos en la jurisprudencia constitucional. Madrid: Universitas.

SANCHA DíEZ, José Pablo (2017). «Derechos de los reclusos en la jurisprudencia del Tribunal Europeo de Derechos Humanos». Revista de Derecho UNED, 21, 455-94. <https://doi.org/10.5944/rduned.21.2017.21170>

SYKES, Gresham M. (1958). The society of captives: A study of a maximum security prison. Princeton (Nueva Jersey): Princeton University Press.

KREAGER, Derek A. y KRUTTSCHNiTT, Candace (2018). «Inmate Society in the Era of Mass Incarceration». Annual Review of Criminology 1, 261-83. <https://doi.org/10.1146/annurev-criminol-032317-092513>

SkARbeK, David (2011). "Governance and Prison Gangs». American Political Science Review, 105 (4): 702-16.

<https://doi.org/10.1017/S0003055411000335> 